\title{
MORIR EN UN "PAIÍS REPUBLICANO": ESTADO, LIBERALISMO Y MUERTE, MENDOZA, SIGLO XIX
}

\author{
Dying in a "Republican Land": State, Liberalism and Death, \\ Mendoza, XIX Century
}

\author{
Gabriela García Garino* \\ Rosana Aguerregaray Castiglione**
}

\begin{abstract}
RESUMEN
El espacio rioplatense asumió tempranamente una vocación republicana y liberal que se manifestó en dispositivos institucionales, legales y políticos, pero también influyó en otros aspectos más generales, como la educación, la salud y la muerte. Este último campo, que había sido dominado por la Iglesia católica, empezó a ser disputado por los nacientes gobiernos surgidos de las revoluciones de independencia. En este sentido, el objetivo de este estudio es analizar la manera en que el discurso republicano fue permeando las formas en las cuales el Estado provincial de Mendoza (Argentina) organizó las formas de morir - específicamente la administración de los cementerios- en el siglo XIX. Como corpus se utilizará la prensa, actas legislativas, leyes, reglamentos, digestos municipales y documentos de autoridades provinciales, municipales y eclesiásticas, sitos en el Archivo General de la Provincia de Mendoza, en el Archivo Legislativo y en el Archivo Diocesano de Mendoza.
\end{abstract}

Palabras clave: Estado, liberalismo, muerte, Argentina.

\begin{abstract}
The former River Plate viceroyalty assumed an early republican and liberal vocation that manifested itself in institutional, legal and political devices, but also influenced other more general aspects, such as education, health and death. This last field, which had been dominated by the Catholic Church began to be disputed by the emerging governments arisen from the revolutions of independence. In this sense, the objective of this paper is to analyze the way in which the republican discourse was permeating the means in which the provincial State of Mendoza (Argentina) organized the forms of dying -specifically the administration of cemeteries- in the century XIX. The corpus is constituted by the press, legislative acts, laws, regulations, municipal digestos and documents of provincial, municipal and ecclesiastical authorities, located in the General Archive of the Province of Mendoza, in the Legislative Archive and in the Diocesan Archive of Mendoza.
\end{abstract}

Key Words: State, liberalism, death, Argentina.

\footnotetext{
* Investigadora, IMESC-IDEHESI-CONICET, UNCuyo. Argentina.

Correo: gabiggarino@gmail.com

** Investigadora, INCIHUSA-CONICET, UNCuyo. Argentina.

Correo: ignacia_aguerregaray@yahoo.com.ar
}

Recepción: 19-12-2018. Aceptación: 11-12-2019. 


\section{Introducción ${ }^{2}$}

En una sesión legislativa de 1868, el diputado Salvador Civit se opuso a un proyecto de ampliación del cementerio público de la ciudad de Mendoza (Argentina), ${ }^{3}$ pues argumentaba que algunas parcelas de aquel tenían "privilejio para no enterrar sino á determinadas personas, en opocicion con las costumbres de un paiz republicano". $\mathrm{A}$ partir de esta frase, surge la pregunta de si las prácticas de inhumación tenían un carácter particular en una sociedad de ese carácter. En este sentido, es necesario indagar qué era lo republicano y en qué medida esto repercutió en las formas en que el Estado administró la muerte.

Estas preguntas se analizan como parte de la cultura política, en tanto conjunto de prácticas, representaciones y actitudes sobre lo político, que articulan y enmarcan el accionar de los sujetos y que, a su vez es transformado por el quehacer de estos (Berstein, 2003; Sirinelli, 2015). A partir del consenso historiográfico de la temprana vocación republicana y liberal que asumió el espacio rioplatense (Sabato, 2006), se trata de ver cómo nociones como "igualdad", "democracia" y "libertad" permearon diferentes aspectos de la vida que no se agotaron en ámbitos considerados específicamente políticos -constituciones, debates parlamentarios, prensa- sino en otros más generales, como la

\footnotetext{
${ }^{2}$ Una versión preliminar de este trabajo fue presentada en las $V$ Jornadas Nacionales y I Internacionales de Investigaciones Regionales Interdisciplinarias "Enfoques para la historia". Realizadas del 30 de agosto al 1 de septiembre de 2017, INCIHUSA, Centro Científico Tecnológico-CONICET, Mendoza. Agradecemos los comentarios de las doctoras Inés Sanjurjo y Eugenia Molina, así como las sugerencias del o la evaluadora.

${ }^{3}$ La ciudad de Mendoza se ubica en el centro oeste de Argentina y fue fundada en 1551, la cual dependía de la Capitanía General de Chile hasta la fundación del Virreinato del Río de la Plata en 1776. Desde entonces fue integrada como corregimiento de Cuyo a la Gobernación Intendencia de Córdoba. Tras su adhesión a la Revolución de mayo de 1810, Cuyo se convirtió en una gobernación, con capital en Mendoza (1813). Con gran autonomía tras la caída del gobierno de las Provincias Unidas, desde 1852 se integraría a la Confederación Argentina que, desde 1862, se denominó República Argentina a partir del avance de Buenos Aires sobre las provincias. Con un territorio mayormente árido, la población se organizó a partir de los oasis alimentados por ríos que descienden de la cordillera de Los Andes. Su actividad era predominantemente comercial, agrícola y ganadera.

${ }^{4}$ Sesión legislativa del 24 de marzo de 1868, Libro de Actas de la Legislatura (Actas...en adelante), Tomo IX: 1866-1870, Archivo Legislativo de Mendoza (ALM en adelante). Se respeta la ortografía y puntuación originales en las citas de las fuentes.
} 
educación, la salud, incluso las formas de vivir y de morir. Problemáticas como la protección de la salud pública, la regulación de las prácticas fúnebres y la administración de los espacios de entierro, que habían sido dominio de la Iglesia católica, empezaron a ser objeto de disputa por parte de los incipientes gobiernos que emanaron de las revoluciones de independencia.

El objetivo de este artículo es analizar cómo los discursos republicanos y liberales fueron permeando las formas en las cuales el Estado provincial de Mendoza organizó los modos de morir -específicamente la administración de los cementerios- en el siglo XIX. Para realizar el trabajo, se presenta un breve panorama sobre los significados de lo republicano, un análisis de los cuerpos normativos que los reglaron -emanados de diferentes autoridades- $\mathrm{y}$ un examen del aspecto fiscal de aquellos establecimientos. Como corpus documental se utiliza la prensa, actas legislativas, leyes, reglamentos, digestos municipales y documentos de autoridades provinciales, municipales $\mathrm{y}$ eclesiásticas, sitos en el Archivo General de la Provincia de Mendoza y en el Archivo Legislativo de Mendoza.

\section{Entre la república, lo republicano y lo liberal}

El abordaje de los significados y usos otorgados por los actores a una palabra en un contexto es una de las herramientas disponibles para analizar una cultura política dada. La historia conceptual, en tanto metodología que trata de reconstruir los múltiples niveles que se articulan en los conceptos, especialmente aquellos que condensan nudos problemáticos en momentos de grandes cambios como las revoluciones liberales de los siglos XVIII y XIX, se presenta como una vía privilegiada para dilucidar qué fue lo republicano, lo liberal y qué implicó para los mendocinos del siglo XIX (Fernández Sebastián, 2007; Koselleck, 2004; Rosanvallon, 2002). 
La consulta a los diccionarios de 1780, 1814 y 1884 ofrece una primera aproximación: en el de 1780 aparecen tres acepciones relacionadas entre sí pero distintas. La república es la "causa pública", el bien o utilidad públicos; la referencia a algunos grupos étnicos como la "república de indios" o la "república de los españoles" y, finalmente, la república como "gobierno de muchos", opuesto al gobierno monárquico. En el de 1817 se mantienen esas acepciones, aunque se va perfilando el término como un gobierno del pueblo, de forma directa o mediante representantes, asociado en ambos casos al término "democracia"; también se presenta esta noción como sinónimo de cualquier cuerpo político organizado o estado, significado que continúan en el léxico de 1884 (Real Academia Española, 2013).

La historiografía sobre el tema concuerda en la polisemia del concepto de república y de lo republicano, ya que coinciden en que, a principios del siglo XIX y antes de las revoluciones de independencia, los significados más usados hacían referencia al "bien público", pero también a una jurisdicción local o municipal, por lo que alguien "republicano" era la persona que servía con celo al bien de su comunidad. Fue solo lentamente y merced a un largo proceso de reelaboración conceptual producto de los vertiginosos cambios sociales y políticos de las décadas revolucionarias, y que a su vez incidió en estos, cuando empezó a predominar la noción de república no solo como forma de gobierno, sino como una forma específica y opuesta a la monarquía (Di Meglio, 2009, pp. 1270-1281; Lomné 2009, pp. 1253-1269).

De acuerdo con Guerra (2000), esta acepción, que inicialmente se había producido como resultado de la vacatio regis tras la invasión francesa a la península española, expresaba la autonomía criolla y fue condensando los sentimientos antimonárquicos que el regreso de Fernando VII y su restauración absolutista produjeron en Hispanoamérica. De esta manera, para la década de 1820, las élites criollas habían pasado de la fidelidad 
monárquica de la década anterior a un prácticamente unánime republicanismo. Esto se traducía en diseños institucionales y constitucionales que sostenían las elecciones periódicas de los gobernantes, derechos individuales, igualdad ante la ley y separación de poderes. Así, un régimen republicano era representativo y liberal en contraste con las democracias asociadas al ejercicio directo de la soberanía por parte del pueblo.

Por su parte, los estratos significantes de lo republicano también incluyeron referencias a la Antigüedad clásica que, pasando por el republicanismo florentino del siglo XVI e inglés del XVII, aludían a la necesaria participación de los ciudadanos en la administración de los poderes públicos, en tanto garantía indispensable para el ejercicio de la libertad pública (Aguilar Rivera, 2002; Caso Bello, 2012; Entin, 2016). Si algunos autores habían visto este republicanismo como opuesto a un liberalismo más preocupado por salvaguardar los derechos individuales de toda intromisión del Estado, Negretto (2007) señala las intersecciones e hibridaciones que mantuvieron ambas corrientes de pensamiento a lo largo de la modernidad occidental.

La trayectoria del republicanismo y liberalismo hispanoamericano es un ejemplo de estos sincretismos, en tanto que un publicista como Juan Bautista Alberdi, ideólogo de la constitución argentina de 1853, encontró respuestas en ambas tendencias al problema que, según Negretto (2007) había atormentado a las dirigencias hispanoamericanas: cómo erigir un orden que no avasallara los derechos individuales en un contexto de inestabilidad y violencia. Así, la respuesta conjugó elementos republicanos, liberales y conservadores, con lo cual se dio lugar a un régimen presidencialista, de un federalismo centralizado, con sufragio universal y amplios derechos civiles para todos los habitantes.

En la prensa mendocina de la segunda mitad del siglo XIX, el término "república" conservó su polisemia. Uno de sus usos más frecuentes, ya presente en la primera mitad de la centuria, hacía del vocablo un concepto de estados o países, como en las "repúblicas 
sudamericanas", además de ser el nombre oficial de Argentina en numerosos documentos como discursos presidenciales, circulares de ministerios, decretos, etc. ${ }^{5}$

Asimismo, también se mantuvo la alusión a república como un tipo específico de gobierno, opuesto, en general, al monárquico y al aristocrático. En este sentido, había varias fórmulas como "sistema", "forma de gobierno", "sociedad" o "régimen" republicano, muchas veces acompañadas de otros términos como "representativo" y “democrático". Lo republicano, además, solía aparecer en cercana asociación con lo liberal. Estas frases incluían una serie de rasgos como la soberanía del pueblo expresada en el sufragio, la igualdad ante la ley, las elecciones periódicas de los gobernantes y, por tanto, el ejercicio del poder mediante representantes electos, la transparencia y publicidad de los actos de gobierno y la división de poderes (García Garino, 2014). Cada uno de estos aspectos era enfatizado, en diversa medida, de acuerdo con las intenciones del articulista de turno. ${ }^{6}$

Por su parte, "lo republicano" como noción o como adjetivo tuvo una importante presencia en los escritos, calificando palabras como "principios", "instituciones", "moral", "libertad" y “constitución", las cuales se han usado como un atributo positivo. En ocasiones, empero, podía ser falseado por quienes se escudaban en él discursivamente

\footnotetext{
5 "Los asuntos de San Juan", E. C. n. ${ }^{\circ}$ 81, 13 de agosto de 1852; "Union americana", El Tupungato (E. T. en adelante) n. ${ }^{\circ} 87,26$ de julio de 1862; "Club Libertad Mendoza. Programa", E. C. n. ${ }^{\circ} 2926,3$ de octubre de 1863; "A los pueblos libres del continente americano", E. C. n. ${ }^{\circ} 3025,7$ de junio de 1864; "Loor al ejército aliado", E. C. n. ${ }^{\circ} 3308,5$ de mayo de 1866; "Lo que significa el Programa del Jeneral Mitre", E. C. n. ${ }^{\circ}$ 419, 31 de enero de 1874; "CANDIDATOS DEL PARTIDO NACIONALISTA DE MENDOZA para Presidente de la República Dr. D. CÁrlos TeJedor para Vice-presidente Dr. D. SATURnino M. Laspiur. Acta", E. P. n. ${ }^{\circ} 53,10$ de noviembre de 1879.

${ }^{6}$ Guizot, "Ceccion literaria", El Constitucional (E. C. en adelante) n. ${ }^{\circ} 11,13$ de mayo de 1852; E. C. n. ${ }^{\circ}$ 2925, 1 de octubre de 1863; "La moral administrativa", E. C. n. ${ }^{\circ} 3074,4$ de octubre de 1864; "Derecho de asociacion", E. C. n. ${ }^{\circ} 3323,16$ de junio de 1866; "Eleccion de Gobernador", E. C. n. ${ }^{\circ} 3360,15$ de septiembre de 1866; "La responsabilidad de los funcionarios públicos", E. C. n. ${ }^{\circ} 3982,14$ de diciembre de 1867; "Deber del ciudadano. Elecciones nacionales", E. C. n. ${ }^{\circ} 105,14$ de diciembre de 1871; "La esperanza", E. C. n. ${ }^{\circ} 308,1$ de mayo de 1873; "Manifiesto del Dr. Alsina. AL pueblo de la República", $E$. C. n. ${ }^{\circ}$ 443, 28 de marzo de 1874; "Consecuencias de la batalla de Santa Rosa", E. C. n. ${ }^{\circ}$ 539, 9 de enero de 1875; "Respeto a los poderes", E. C. n. ${ }^{\circ} 1125,22$ de octubre de 1878.

7 "Proccimidad de la jura", E. C. n. ${ }^{\circ} 344,6$ de julio de 1653; "Eleccion de convencionales", E. C. n. ${ }^{\circ} 3337$, 19 de julio de 1866; "Monumento", E. C. n. ${ }^{\circ} 216,24$ de septiembre de 1872.
} 
mientras su conducta se contradecía con el término. En este sentido, los autores aludían a "republicanos disfrazados". 8

Sin embargo, hubo excepciones a la valoración predominantemente favorable del concepto. Así, en un escrito se habló de "republicanos a la commune" para descalificar a las personas que habrían fraguado una elección en favor del candidato oficial. ${ }^{9}$ También se utilizó la expresión "huracan republicano", con la cual se refería a un impulso que arrasaba con el status quo quizás sin que estuvieran las condiciones dadas -en este caso una extensión suficiente de la educación entre los habitantes- para el establecimiento de instituciones republicanas, mientras que en otros casos se asociaban las “ajitaciones politicas y el espiritu de oposicion" a los regímenes republicanos. ${ }^{10}$ Lo mismo ocurrió cuando un jefe de policía se quejó de cierta laxitud en la moral, propia de las “pueblos republicanos" que permitía que cualquier persona atacara impunemente el buen nombre de otro. ${ }^{11}$

En este sentido, la educación del pueblo aparecía como un requisito indispensable de un régimen republicano y liberal, puesto que preparaba a los ciudadanos para ejercer el sufragio y participar activamente de la construcción de la república, al hacerlos conscientes de la importancia de su rol para la vida comunitaria. Se percibe, entonces, el hilo del republicanismo clásico, que exigía una participación activa de los ciudadanos en los aspectos comunes a fin de proteger la libertad, y a la república como fruto de un aprendizaje constante y comunitario. ${ }^{12}$

\footnotetext{
8 "El fondo", E. C. n. ${ }^{\circ} 1395,17$ de julio de 1880.

${ }^{9}$ Aguirre, L., "Por respeto a la familia", E. C. n. ${ }^{\circ} 40,11$ de julio de 1870.

10 “AA dónde vamos?”, E. C. n. ${ }^{\circ} 1331,3$ de diciembre de 1856; "Correspondencia. Algo sobre educacion”, E. C. n. ${ }^{\circ} 3306,1$ $^{\circ}$ de mayo de 1866; "El hombre público i el privado", E. C. n. ${ }^{\circ} 3950,1$ de octubre de 1867. ${ }^{11}$ Villanueva, J., “A mis amigos", E. T. n. ${ }^{\circ} 194,13$ de febrero de 1863.

12 "Movimiento administrativo II", E. C. n. 3309, 8 de mayo de 1866; "Indiferentismo", L. O. n. ${ }^{\text {o } 13,13}$ de enero de 1870; "Elecciones", E. C. n. ${ }^{\circ}$ 510, 12 de septiembre de 1874; Civit, F., "Discurso pronunciado por el Gobernador de la Provincia, al abrir las sesiones de la Honorable Cámara Lejislativa de 1875", E. C. n. ${ }^{\circ}$ 552, 11 de febrero de 1875; "Educar al pueblo es gobernarlo", E. C. n. ${ }^{\circ}$ 585, 4 de mayo de 1875.
} 
Otro de los significados de mayor incidencia en este campo semántico es la idea de “igualdad" ${ }^{13}$ En general, esta era una igualdad política que se reflejaba en el sufragio universal, esa revolución radical investigada por Pierre Rosanvallon (1992) de "un hombre, un voto". ${ }^{14}$ Ahora bien, para que el sufragio realmente equivaliera a la soberanía popular, fundando un régimen republicano, este no debía ser falseado o fraguado, ya por el dinero, la violencia u otros medios espurios. ${ }^{15}$ La igualdad política a veces se extendía hacia la elegibilidad de los cargos, manifestándose cuando se pidió a los convencionales que eliminaran los requisitos de renta para cualquier cargo electivo, por considerarlos “aristocráticos". ${ }^{16}$ Finalmente, en otros casos, la igualdad parecía teñir lo social, por ejemplo en la carta de un funcionario que respondía a quienes lo atacaban por su falta de linaje familiar, o cuando se exigía que la justicia aplicara la ley sin reparar en la filiación social de los acusados. ${ }^{17}$

\section{Las normas y la muerte: la reglamentación de los cementerios}

\section{públicos}

En el año 1828, el entonces gobernador de la provincia, Juan Corvalán, había sancionado la ley que establecía la creación de cementerios públicos. En esta, se determinaba que la edificación de estos establecimientos debía realizarse en las afueras

\footnotetext{
${ }^{13}$ Hubo algunas excepciones a esta asociación -casi equivalencia- entre régimen republicano e igualdad. Así, en ocasiones se diferenciaba la república de la democracia, expresando que en la primera se toleraban privilegios y explotaciones impensables en la segunda. Ver "El Poder Judicial de la Confederacion", E. C. n. ${ }^{\circ}$ 1401, 28 de febrero de 1857; "La institucion Municipal", E. C. n. ${ }^{\circ} 426,17$ de febrero de 1874.

14 "Sesion notable", E. C. n. ${ }^{\circ} 1303,29$ de octubre de 1856; "Elecciones", E. T. n. ${ }^{\circ} 180,17$ de enero de 1863; Editorial, E. C. n. ${ }^{\circ}$ 3365, 27 de octubre de 1866; Civit, F., "Mensaje del gobernador de la provincia al abrir el segundo periodo de sesiones ordinarias, de la cámara lejislativa en 1874", E. C. n. ${ }^{\circ} 494,4$ de agosto de 1874; "Discurso del Dr. Avellaneda", E. C. n. ${ }^{\circ} 546,26$ de enero de 1875.

15 "El manifiesto del Dr. Cortínez", E. C. n. ${ }^{\circ} 2973,26$ de enero de 1864; "Los que pretenden ganarse el voto del pueblo corrompiéndolo no obran de buena fe", E. C. n. ${ }^{\circ} 3366,29$ de septiembre de 1866; "La práctica de la inmoralidad", E. C. n. ${ }^{\circ} 4031,7$ de abril de 1868; "La guardia nacional", La Libertad n. ${ }^{\circ} 40$, 5 de julio de 1872; "Cámara Lejislativa. La sesion del mártes", E. C. n. ${ }^{\circ} 360,4$ de septiembre de 1873.

16 "La convencion", E. C. n. ${ }^{\circ} 924,7$ de julio de 1877.

17 “Comunicados", E. C. n. ${ }^{\circ} 455,28$ de abril de 1874; "Igualdad ante la ley", E. C. n. ${ }^{\circ} 529,17$ de diciembre de 1874 .
} 
de la ciudad y se prohibía el entierro en el interior de las iglesias y sus cercanías. Todos los cadáveres debían ser sepultados en los cementerios sin distinción de "claces, fueros, privilegios, usos ni costumbres $"{ }^{18}$ pues debían albergar a todos los ciudadanos por igual. Además, determinaba que en el interior se realizaría la edificación de una capilla y una habitación para el capellán, aunque su ausencia no debía ser motivo para que no se efectuaran las sepulturas. Por lo tanto, era el Gobierno quien fijaba el reglamento, así como también el precio que se debía solventar para ser enterrado. ${ }^{19}$ De hecho, el cuidado del espacio y los ingresos quedaban en manos de la policía. No obstante, esta ley no fue cumplida por la población mendocina de la época.

En esta primera normativa, se advierte una de las acepciones más usuales de lo "republicano" en tanto igualdad ante la ley, al establecer que todas las personas, sin distinción alguna, debían ser sepultadas en el nuevo ámbito destinado a ello: el cementerio de Mendoza. Además, se percibe la fuerte incidencia de la religión católica, lo cual se desprendía de su rol como culto oficial del Estado, en la importancia de la construcción dedicada al ejercicio de los ritos religiosos, como la capilla.

Como el reglamento de 1828 no se puso en práctica, en 1843 el gobernador Félix Aldao dictó un decreto en el cual establecía que el cementerio general debía construirse en el lugar denominado la capilla del Rosario. Asimismo, se conformaría una comisión integrada por ciudadanos distinguidos y el cura y vicario Jorge Corvalán para que realizaran el reglamento, sobre todo "aquello [que] sea útil y conducente al buen orden, sostenimiento y estabilidad" del establecimiento, luego lo debían presentar al Gobierno para su correspondiente aprobación. ${ }^{20}$

\footnotetext{
${ }^{18}$ Doc. 4: "Resolución de leyes, decretos y acuerdos vigentes en la provincia dictados por tres poderes desde 1811 hasta 1834", carpeta 199: Cementerios (1811-1889), Época Independiente, AGPM.

19 Doc. 4: "Resolución de leyes, decretos y acuerdos vigentes en la provincia dictados por tres poderes desde 1811 hasta 1834", carpeta 199: Cementerios (1811-1889), Época Independiente, AGPM.

${ }^{20}$ Doc. 5: "Recopilación de leyes y decretos desde 1834 hasta 1843", carpeta 199: Cementerios (18111889), Época Independiente, AGPM. No se ha encontrado un reglamento elaborado por dicha comisión en
} 
Posteriormente, el 30 de diciembre de 1845, se dictó el mencionado reglamento. Por un lado, este pautaba que el administrador debía exigir la presentación del boleto de sepultura, el cual sería otorgado por el cura de la ciudad y contendría los siguientes datos: nombre, sexo, edad, estado y causa de muerte; los derechos obtenidos serían divididos entre el párroco y el administrador. Además, el encargado revisaría los "libros de asiento" realizados por el capellán y también llevaría un libro de entradas, en él se detallaba los ingresos por derechos de sepultura y conducción de cadáveres que luego sería remitido al jefe de policía para su control y su entrega al Gobierno. ${ }^{21}$

Por otro lado, el reglamento determinaba que el establecimiento contaría con un carro fúnebre de primera clase que costaría un peso y uno de segunda que valdría cuatro reales. Estos coches debían retirar los cadáveres de la casa mortuoria y, en caso de ser inaccesible el sitio, el administrador acordaría un lugar con los deudos para que los restos fueran recogidos y conducidos al cementerio.

La normativa también reglamentaba las funciones que debían cumplir los empleados del cementerio. De este modo, determinaba que el capellán debía asistir todos los días con el fin de inhumar a los cadáveres y rezar los oficios correspondientes. El entierro debía realizarse según el orden en que hubieran sido colocados en el depósito, sin distinción de clase "ni de persona", y desde allí el cuerpo sería acompañado por el capellán hacia el lugar de sepultura, en donde se realizaría el rito correspondiente. También debía asentar la defunción en el libro de partida, anotando los siguientes datos: sexo, estado (soltero, casado, viudo), color y origen (libre o esclavo), otorgados por los allegados al difunto (Ahumada, 1860). Asimismo, le correspondía cuidar que los deudos "guarden el mayor decoro" en la sala de depósito y en el cementerio, en especial en la

${ }^{21}$ Doc. 10: "Compilación de leyes, decretos, reglamentos de la Provincia de Mendoza", desde el 28 de septiembre de 1844 hasta el 11 de marzo de 1850; carpeta 199: Cementerios (1821-1892), Época Independiente, AGPM. 
celebración de las ceremonias religiosas. Igualmente sería su obligación dar misa en sufragio por el alma de los difuntos y rezar todas las noches el rosario y un responso con los fieles que asistieran a la capilla. Este debía autorizar el pedido de disecación y de exhumación de un cadáver en el caso de que un juez lo solicitara, para ello debía llevarse a un sitio profano del establecimiento. En cuanto a las restricciones, estaba prohibido dar sepultura antes de las 24 horas de declarado muerto y pasado el Ave María. Además, tenía vetado depositar los cuerpos en la iglesia (ya que estos debían ir a la sala de depósito como se mencionó) y dar alguna clase de solemnidad al oficio de sepultura. Tampoco podía cantar en ella misas solemnes de requiem ni de vigilia, a excepción de que fuese autorizado por el cura de ciudad. Por los servicios prestados no recibiría más emolumento que doce reales por cada misa de cuerpo presente y dos reales por cada certificado de muerte expedido.

Otro artículo disponía la jerarquización del espacio de inhumación, de este modo los costados oeste y norte del cementerio serían destinados al entierro de los pobres de solemnidad, mientras que el resto de las tierras serían vendidas a la población que deseara comprarlas. Se destinarían sitios específicos para aquellos sujetos que hubiesen desempeñado cargos públicos y políticos, como gobernadores, representantes, camaristas y aquellos individuos que por sus virtudes y servicios fueran relevantes para la patria. Las ganancias obtenidas de los entierros junto a las obvenciones parroquiales y la prestación de los carros fúnebres serían destinadas al pago de los empleados del cementerio, a su mantenimiento y a las refacciones que se realizaran.

En enero de 1846, la Legislatura dictó la resolución que aprobaba el establecimiento del cementerio de ciudad (1828) y su reglamento (1845) y pautaba que serían reembolsados a la policía los gastos que había ocasionado su construcción (Verdaguer, 1933). Unos meses después, el 20 de julio de 1846, el gobernador Pedro Pascual Segura 
reiteró por decreto la obligación de realizar los entierros en el nuevo cementerio de ciudad, y prohibió las inhumaciones en iglesias y conventos "conforme á las leyes asi jenereales, como de la Provincia, fundadas en consideraciones de policía y salubridad pública, y en armonía con el principio relijioso y la costumbre de los pueblos civilizados” (Ahumada, 1860). Al mismo tiempo, manifestaba que el cura y vicario, junto con el Poder Ejecutivo, determinarían el día en el cual se realizaría la consagración del establecimiento religioso. Por otra parte, aclaraba que el jefe de policía quedaría encargado de la ejecución del decreto referido. ${ }^{22}$

Si bien hasta 1845-1846 no se hizo efectiva a toda la población del curato de ciudad la disposición de efectuar los entierros en el cementerio, durante los años 1842 y 1843 fueron sepultados doce cadáveres, aunque el establecimiento se encontraba en construcción. En efecto, el cura interino manifestó en el libro de defunciones que estos sujetos habían sido sepultados sin su licencia (Caballero, 2006).

En este reglamento se seguía expresando una vocación republicana, al fijar su obligatoriedad para todos los ciudadanos, al realizar las inhumaciones por orden de llegada y en la prohibición estricta de privilegiar algunos difuntos mediante ceremonias especiales. De esta manera, las pautas sobre los cementerios parecieron responder a uno de los elementos más caros al sistema republicano: la igualdad ante la ley. La posibilidad de enterrar a exfuncionarios públicos en un sector especialmente delimitado para ellos no era contradictoria con el ideario republicano, ya que no traducía diferencias de origen, sino el mérito adquirido a lo largo de una carrera al servicio del Estado, un rasgo que hacía específicamente a lo "republicano" como se vio al analizar sus significados.

Algunas innovaciones dan cuenta de que la igualdad a la que se aludía en los reglamentos era estrictamente política, legal y formal, lo cual era compatible con un

\footnotetext{
${ }^{22}$ Doc. 10: "Compilación de leyes, decretos, reglamentos de la Provincia de Mendoza", desde el 28 de septiembre de 1844 hasta el 11 de marzo de 1850; carpeta 199: Cementerios (1821-1892), Época Independiente, AGPM.
} 
republicanismo que, en general, no tiñó las relaciones sociales. Entre estos elementos se menciona la posibilidad de acceder a servicios diferenciados en función de la tarifa pagada o la existencia de sectores distintos para las personas que podían pagar y los pobres de solemnidad, que debían acogerse a la caridad pública.

Algunos actores de la época, como el diputado Salvador Civit fueron conscientes de las tensiones que disposiciones como la existencia de sectores diferenciados producían en la práctica del republicanismo. Justamente en ese tipo de consideraciones, el legislador había rechazado el proyecto de ampliación del cementerio, pues consideraba inviable que en un cementerio republicano algunas personas se negaran a compartir espacio con otras. $^{23}$

Pero si la existencia de servicios de calidad diversa puede hablar de una sociedad de clases y no de estamentos, donde el acceso estaba determinado por el dinero y no por el nacimiento, otros elementos resultan más complejos de acomodar a la prédica republicana. Así, la obligación de los párrocos de efectuar listados de los sepultados que junto a datos más estadísticos como la edad, el sexo, la causa de muerte o la situación conyugal, incluían otros indicadores como el "color" y el "origen" (libre o esclavo), que parecían estar más en pugna con un Estado republicano, el cual, supuestamente, ya no prestaba atención a estas diferencias de nacimiento. En este sentido, un análisis sobre padrones electorales para otras provincias argentinas ha dado cuenta de que las clasificaciones fenotípicas -“rubio, trigueño, cobrizo, negro", etc. - implicaban una continuidad con las clasificaciones coloniales -“español, indio, mulato, negro”, etc. -; lo que en última instancia sugiere la persistencia de prejuicios socio-raciales más allá de las transformaciones políticas (Fonseca y Caraffini, 2015). Se debe destacar que uno de los empleados del cementerio, el capellán, era agente de la Iglesia católica y debía celebrar

\footnotetext{
${ }^{23}$ Sesión legislativa del 24 de marzo de 1868, Actas... t. IX, ALM.
} 
misas periódicamente, lo cual permite plantear dudas respecto de si un cementerio público estaba abierto a personas que no profesaran la fe católica. El influjo de este empleado también se evidencia en que de él dependían las autorizaciones para exhumar un cuerpo.

En el reglamento de 1882, se estableció la necesidad de poseer un certificado médico en donde constara la causa de muerte y los siguientes datos: parroquia, sección, cuartel, nombre, apellido, sexo, estado, color, nacionalidad, domicilio, profesión, edad, nombres de los padres, enfermedad o causa presunta de muerte, día y hora de defunción, estos como instrumentos que formaban parte de una praxis médico-legal en formación, en la cual la voz del doctor o facultativo iba constituyéndose en fiable y esclarecedora. Así, de forma progresiva, este proceso de medicalización buscó ocupar nuevos espacios y obtener una mayor legitimación para intervenir en la sociedad, como un componente fundamental del proceso de modernización estatal (Riva, 2011). Respecto a los empleados del cementerio, el capellán y el sepulturero, no se modificaron las funciones establecidas en reglamentos anteriores.

En cuanto a la inhumación de cadáveres, aún con mayor detalle que en las normas anteriores, se establecía que esta se realizara con el permiso de la autoridad correspondiente, a partir de este momento, el médico. En caso de que los deudos o allegados no indicaran el lugar de sepultura del cadáver, sería depositado en la fosa común. Además, se determinaba que los cuerpos provenientes de hospitales, cárceles o departamento de policía debían ser sepultados en cajones por separado e inscriptos en libros especiales. Los entierros para las personas pobres debían ser gratuitos, previa certificación de la municipalidad, hospital, cuartel o policía; y en época de epidemia estipulaba que todos los cadáveres que fueran sepultados sin cajón debían ser rociados con cal. Por último, se disponía que no habría excepciones a esta ley. ${ }^{24}$

\footnotetext{
${ }^{24}$ Digesto Municipal de la Ciudad de Mendoza 1868-1886, Buenos Aires, Imp. de M. Biedma, 1887.
} 
En lo que concierne al valor de los derechos de sepultura, se determina que en los cuadros destinados a las comunidades religiosas se pagarían diez pesos fuertes por fosa temporal y veinte a perpetuidad. En el cuadro general, cuatro pesos fuertes por fosa temporal y treinta a perpetuidad. Si los terrenos eran para edificar mausoleos, se cobraría cuatro pesos fuertes por metro cuadrado.$^{25}$ Esto señala otra innovación respecto de la organización del espacio; ya no solo se dividiría entre quienes podían costear sus exequias y quienes debían acudir a la caridad pública, sino que se añadía un sector para los miembros de comunidades religiosas.

El nuevo reglamento da cuenta de la profundización del avance de Estado sobre los cementerios, como indica el hecho de que la autorización para el entierro de un cadáver ya no emanaba del cura párroco sino de un médico, lo cual implicaba una mayor confianza estatal en el discurso científico. Las ideas republicanas, a su vez, se vislumbraban en la insistencia de que todas las personas debían someterse a este reglamento, empero, se abría la posibilidad a disfrutar de calidades diferenciadas en función del pago. Finalmente, se reiteraba la necesidad de que los certificados de defunción especificaran datos como la nación, el color y la profesión. Resulta interesante la intención de asegurar una mayor diferenciación entre los ámbitos de la Iglesia y el Estado, como muestra la transferencia por parte de las funciones del capellán a un médico y el establecimiento de un sector específico para la inhumación de los miembros de congregaciones religiosas.

El paso de la administración de la muerte al ámbito estatal también puede observarse a través de las erogaciones que aquel servicio exigió. A continuación, se ofrece una mirada exploratoria de este aspecto. 


\section{Las erogaciones de la muerte: el aspecto fiscal}

El gobierno de Mendoza procuró que los cementerios se financiaran de forma autónoma a través del cobro de derechos de sepultura. Estos incluían, por un lado, la mitad de lo que percibía el párroco correspondiente por emitir el boleto de sepultura sin el cual un cuerpo no podía ser enterrado y, por otro, el pago de los servicios de traslado y la compra de la parcela. Las tarifas de ambos servicios dependían de la "calidad" que los interesados estuvieran dispuestos a pagar, ya que había dos clases; el monto también estaba ligado al tiempo de uso de la sepultura -dos años, diez renovables o a perpetuidadcomo a la ubicación de la parcela. Finalmente, había excepciones para quienes fueran considerados "pobres de solemnidad", que costeaban la mitad de los derechos parroquiales y podían acceder a espacios del cementerio reservados para ellos. ${ }^{26} \mathrm{Se}$ trataba de una categoría jurídica que exigía el cumplimiento de ciertos requisitos y una sanción por parte de los órganos correspondientes (Caretta y Zacca, 2010, 2007; Fogelman, 2004).

Más allá de la existencia de los cánones para el cementerio, este no logró ser autosuficiente, lo que exigió una considerable erogación del Estado provincial en este rubro. El cuadro 1 da cuenta de los gastos realizados entre 1845 y 1850 , y confirma un fenómeno analizado en el apartado anterior: por una parte, la existencia de legislación desde una fecha tan temprana como 1828 no implicó la puesta en práctica de aquella, sino que recién en 1845 el cementerio aparece como uno de los índices de los estados de cuenta, ya de la provincia o de la policía. Por otra parte, el elevado monto de 1845, el cual nunca más sería igualado, probablemente señala los cuantiosos gastos que implicó su

\footnotetext{
${ }^{26}$ Ley que aprobaba el reglamento de cementerios del 5 de julio de 1848, doc. 4: Recopilación de leyes, decretos y acuerdos vigentes en la provincia dictados por tres poderes desde 1811 hasta 1834; Ley de adición al reglamento de 1828 del 12 de mayo; doc. 10: Compilación de leyes, decretos, reglamentos de la Provincia de Mendoza, desde el 28 de septiembre de 1844 hasta el 11 de marzo de 1850; carpeta 199: Cementerios (1821-1892), Época Independiente, AGPM.
} 
construcción y, luego, el hecho de que implicó una fuente de déficit permanente del Estado.

Cuadro 1: Gastos en el cementerio de ciudad ${ }^{27}$

\begin{tabular}{|l|l|}
\hline Año & Gastos \\
\hline 1845 & 1992 pesos \\
\hline 1846 & 279 pesos 4 reales \\
\hline 1847 & 152 pesos 3 reales \\
\hline 1848 & 125 pesos 4 reales \\
\hline 1849 & 7 pesos 6 reales \\
\hline 1850 & 135 pesos $1 / 2$ real \\
\hline
\end{tabular}

Fuente: Elaboración propia a partir de datos obtenidos de las colecciones de Registros Ministeriales entre 1845 y 1850 y de documentos de la carpeta 16 del AGPM.

En los presupuestos provinciales disponibles desde 1853, el cementerio de ciudad tuvo una partida -que incluía los sueldos del administrador, el capellán, el sepulturero y el carrero- hasta 1869, lo cual explica por qué las primeras municipalidades se establecieron aquel año. Del mismo modo, también se preveía una entrada por las rentas del mencionado establecimiento que generalmente era inferior a las salidas con la salvedad de 1853, como se ve en el cuadro 2:

Cuadro 2: Entradas y salidas del cementerio de ciudad en los presupuestos provinciales

\begin{tabular}{|l|l|l|}
\hline Año & Entradas & Salidas \\
\hline 1853 & 611 & Administrador: 16 pesos por mes \\
& pesos & $\begin{array}{l}\text { Capellán: 16 pesos por mes } \\
\text { Sepulturero: 8 pesos y 6 reales por mes }\end{array}$ \\
\hline
\end{tabular}

\footnotetext{
${ }^{27}$ Se han encontrado datos de junio a diciembre de 1845 en los gastos efectuados por la policía. Registro Ministerial (R. M. en adelante) n. ${ }^{\circ}$ 11, diciembre de 1845, Época Independiente, AGPM. 1846 comprende todos los meses, Doc. 3: "Cuaderno de cargo y data del Cementerio para los años 1846-1848 y 49-50-51", carpeta 16: Cementerios (1816-1876), Época Independiente, AGPM. El año 1847 está completo salvo por octubre y diciembre, ya que los estados de cuenta correspondientes no incluyeron datos sobre cementerio. R. M. n. ${ }^{\circ} 24,25,27,29,30,31$ y 34 de 1847, Época Independiente, AGPM. Para 1848 se hallaron datos de todos los meses al combinar los estados de la caja provincial y de la policial, que resultaron complementarios, $R$. M. n. ${ }^{\circ}$ 36, 44, 45, 47 de 1848, Época Independiente, AGPM. El año 1849 comprende los meses de febrero, marzo, abril, mayo, septiembre, octubre y noviembre. Doc. 3: "Cuaderno de cargo y data del Cementerio para los años 1846-1848 y 49-50-51", carpeta 16: Cementerios (1816-1876), Época Independiente, AGPM. 1850 está completo Doc. 7: "Entradas y salidas del Cementerio durante el año 1850", carpeta 16: Cementerios (1816-1876), Época Independiente, AGPM. Cabe destacar que en otro documento se ofrece otra serie de datos que dan la suma de 114 pesos y 6,5 reales, sin que sea posible saber cuál es más fidedigna. Ver Doc. 3: "Cuaderno de cargo y data del Cementerio para los años 1846-1848 y 49-50-51", carpeta 16: Cementerios (1816-1876), Época Independiente, AGPM.
} 


\begin{tabular}{|c|c|c|}
\hline & & $\begin{array}{l}\text { Carrero: } 7 \text { pesos y } 6 \text { reales por mes } \\
\text { Total: } 582 \text { pesos por año }\end{array}$ \\
\hline 1857 & 30 pesos & $\begin{array}{l}\text { Cera y vino para las misas: } 18 \text { pesos por año } \\
\text { Velas de cebo y lavado de ropa para la iglesia: } 18 \text { pesos por año } \\
\text { Reparación de los ornamentos: } 25 \text { pesos por año } \\
\text { Sueldo del capellán: } 16 \text { pesos por mes, } 192 \text { anuales } \\
\text { Sueldo del administrador: } 16 \text { pesos por mes, } 192 \text { anuales } \\
\text { Sueldo del sepulturero: } 10,5 \text { por mes, } 126 \text { anuales } \\
\text { Sueldo del sacristán: } 3 \text { pesos por mes, } 36 \text { anuales } \\
\text { Reparaciones en los departamentos y paredes del contorno: } 40 \\
\text { pesos por año } \\
\text { Construcción de osario común: } 100 \text { pesos por año } \\
\text { Total: } 843 \text { pesos por año }\end{array}$ \\
\hline 1864 & $\begin{array}{l}100 \\
\text { pesos } \\
\text { por año }\end{array}$ & $\begin{array}{l}\text { Sueldo del administrador: } 25 \text { por mes, } 300 \text { por año } \\
\text { Sueldo del capellán: } 16 \text { por mes, } 192 \text { por año } \\
\text { Sueldo del sepulturero: } 10 \text { por mes, } 120 \text { por año } \\
\text { Sueldo de un carrero, } 10 \text { por mes, } 120 \text { por año } \\
\text { Total: } 732 \text { pesos por año }\end{array}$ \\
\hline 1865 & $\begin{array}{l}362 \\
\text { pesos }\end{array}$ & $\begin{array}{l}\text { Sueldo del administrador: } 25 \text { por mes, } 300 \text { por año } \\
\text { Sueldo del capellán: } 16 \text { por mes, } 192 \text { por año } \\
\text { Sueldo del sepulturero: } 10 \text { por mes, } 120 \text { por año } \\
\text { Sueldo de un carrero: } 10 \text { por mes, } 120 \text { por año } \\
\text { Total: } 732 \text { pesos por año }\end{array}$ \\
\hline $\begin{array}{l}1867 \\
\text { (desde } \\
\text { junio) }\end{array}$ & $\begin{array}{l}350 \\
\text { pesos }\end{array}$ & $\begin{array}{l}\text { Sueldo del administrador: } 25 \text { por mes, } 175 \text { por año } \\
\text { Sueldo del capellán: } 20 \text { por mes, } 140 \text { por año } \\
\text { Sueldo del sepulturero: } 12 \text { por mes, } 84 \text { por año } \\
\text { Sueldo del carrero: } 12 \text { por mes, } 84 \text { por año } \\
\text { Total: } 483 \text { pesos por año }\end{array}$ \\
\hline 1868 & 300 & $\begin{array}{l}\text { Sueldo del administrador: } 20 \text { por mes, } 240 \text { por año } \\
\text { Sueldo del capellán: } 20 \text { por mes, } 240 \text { por año } \\
\text { Sueldo del sepulturero: } 12 \text { por mes, } 144 \text { por año } \\
\text { Sueldo del carrero: } 12 \text { por mes, } 144 \text { por año } \\
\text { Total: } 828 \text { pesos por año }\end{array}$ \\
\hline 1869 & $\begin{array}{l}300 \\
\text { pesos }\end{array}$ & $\begin{array}{l}\text { Sueldo del administrador: } 20 \text { por mes, } 240 \text { por año } \\
\text { Sueldo del capellán: } 20 \text { por mes, } 240 \text { por año } \\
\text { Sueldo del sepulturero: } 12 \text { por mes, } 144 \text { por año } \\
\text { Sueldo del carrero: } 12 \text { por mes, } 144 \text { por año } \\
\text { Total: } 828 \text { pesos por año }\end{array}$ \\
\hline
\end{tabular}

Fuente: Elaboración propia a partir de las leyes de presupuesto del ROPM.

Junto a estos números, las fuentes también indican que los cementerios insumían mayores gastos de las entradas que generaban, es decir, resultaban deficitarios. Cuando pasaron al ámbito municipal, esta situación no cambió, ya que eran habituales las notas 
de subdelegados y municipalidades pidiendo ayuda para reparar un cementerio o para

fundar uno nuevo. Este último caso se dio en los departamentos de Godoy Cruz, Guaymallén y Maipú, que si bien contaban con un camposanto, solicitaron fondos para refaccionarlo completamente o erigir uno nuevo, aludiendo diversas causas como demasiada cercanía al centro urbano, inundaciones o sobrepoblación del terreno. En todos los casos, se esgrimía la salud e higiene del vecindario como razón postrera. ${ }^{28}$ En última instancia, estas cifras ilustran que, pese a la sangría que implicaba el cementerio a un siempre escaso erario provincial, las autoridades consideraron indispensable cierta inversión en este rubro, a fin de resguardar la salud pública.

\section{Reflexiones finales}

El recorrido alrededor de las normas y finanzas sobre el cementerio de la ciudad de Mendoza ha mostrado el lugar de privilegio que este ocupó para las autoridades. Con el objetivo fundamental de promover la higiene y la salud pública, se destinaron no solo

\footnotetext{
${ }^{28}$ Doc. 76: "Don Joaquín Villanueva al Ministro de Gobierno referente a la expropiación de terrenos para ensanchar el cementerio. Adjunta un plano donde figura el terreno que se necesita", Mendoza, 13 de diciembre de 1871; doc. 89: "Don Joaquín Villanueva al Ministro de Gobierno referente a la expropiación de terrenos para agrandar el cementerio, pues según el administrador del mismo, asegura no tener lugar para sepultar más cadáveres", Mendoza, 19 de marzo de 1872, carpeta 133: Municipalidad de Capital (1857-1871); doc. 38: "Don Carlos María Videla al Ministro de Gobierno, referente a la instalación de un cementerio en el Departamento de Guaymallén", 9 de noviembre de 1870, carpeta 267: Correspondencia (1853-1893); doc. 107: "Hilarión Leiva al secretario de gobierno. Necesidad de trasladar el Panteón", Mendoza, 28 de octubre de 1864, carpeta 516: Departamento de Godoy Cruz (1812-1864); doc. 37: El subdelegado de Godoy Cruz, Emilio Blanco, al ministro de gobierno eleva notas relativas a la instalación del nuevo cementerio, 2 de junio de 1868; carpeta 517: Departamento de Godoy Cruz (1865-1873); doc. 18: "F. Raffo al Ministro de Gobierno, informa sobre trabajos en el Cementerio municipal", 26 de abril de 1872, doc. 27: "Manuel Olmedo al Ministro de Gobierno remite cuenta de los gastos realizados en el cementerio departamental", 3 de julio de 1872, carpeta 523: Departamento de Guaymallén (1872-1873); doc. 31: "Guillermo Molina al Ministro de Gobierno, transcribe nota referente al mal estado del cementerio", 3 de marzo de 1881, carpeta 524a: Departamento de Guaymallén (1876-1879); doc. 28: "Don Joaquín Villanueva al Ministro General de Gobierno, referente a la falta de fondos para atender las necesidades del cementerio. Sugiere la conveniencia de cobrar derechos de sepultura para solventar los gastos indispensables", 4 de julio de 1862; doc. 51: "Presupuesto presentado al Ministro de Gobierno para el nuevo Cementerio de Godoy Cruz", 25 de enero de 1868, carpeta 16: Cementerios (1816-1876); doc. 1: "A. Vasquez y otros al Sr. Subdelegado envían presupuesto para construcción de cementerio", 23 de enero de 1865; doc. 4: "Blas Barrera al Mtro. De Gobierno acerca de la construcción de un cementerio", 23 de enero de 1865; doc. 10: "Blas Barrera al Mtro. Secretario de Gob. envía nota acerca de la necesidad de concluir el cementerio", 3 de abril de 1865, carpeta 533bis: Departamento de Maipú (1865-1867), AGPM.
} 
importantes sumas a su construcción y refacciones -más allá de que estas siempre eran insuficientes a la luz de los diversos encargados-, sino varias normas para ordenar y especificar su funcionamiento.

Si bien se procuró que el cementerio se autofinanciara mediante los cánones que debían pagar las personas para el traslado de los cuerpos, la celebración de los oficios y la adquisición de las parcelas, el examen de las cuentas del establecimiento muestra que esto no fue posible y que el Estado - a nivel provincial en un primer momento y municipal luego- debió invertir considerables sumas en su mantenimiento. Este hecho confirma lo que se ha sugerido respecto a la relevancia de los panteones en el ideario de la dirigencia mendocina del siglo XIX.

La pregunta inicial que funcionó como hilo conductor del trabajo aludía a la especificidad de las formas de reglar la muerte por parte de un Estado que se decía republicano. Para ello, se analizaron los diversos significados y términos articulados por "lo republicano", lo cual dio cuenta de varios niveles. En primer lugar, uno que aludía al bien común, más propio del período tardocolonial y, luego, un paulatino proceso de particularización mediante el cual lo republicano se constituyó en opuesto a lo monárquico y, por esta vía, condensó un régimen político que, entre otros rasgos, se caracterizó por la igualdad ante la ley. En este sentido, lo republicano también se imbricó fuertemente con lo liberal y lo conservador, lo que muestra la hibridación que caracterizó la construcción de los estados hispanoamericanos.

Las ideas republicanas, como parte del caldo ideológico del siglo XIX, no se limitaron al ámbito político, sino que permearon cada aspecto de la sociedad. El cementerio no fue una excepción. Así, el análisis de los cuerpos que rigieron sobre las prácticas mortuorias da cuenta de la incidencia del republicanismo en ellas, especialmente la noción de la igualdad de las personas, sin distinción de ninguna clase, ante la ley. De 
esta manera, toda la normativa insistió en la uniformidad jurídica, es decir, en que toda la población debía someterse, sin excepción alguna, a la nueva norma. En la misma línea, se prohibió cualquier tipo de ceremonias solemnes que destacaran algunas exequias sobre las otras.

Sin embargo, los cuerpos reglamentarios permitieron otro tipo de diferenciaciones -en la ubicación y tiempo de usufructo de las parcelas, en la calidad del servicio- que respondían a las posibilidades económicas de los deudos. Es decir, que la igualdad republicana que subyacía a las normas, se limitaba a lo político y formal, pues se permitieron distinciones económicas. Si estas diferencias podían ser compatibles con lo republicano, otro tipo de disposiciones como la exigencia de asentar en los libros de defunciones características como el "color", el "origen” y la profesión, parecen más difíciles de ubicar en un régimen político que se definía de este modo.

Tampoco se puede obviar la fuerte incidencia del catolicismo, en tanto culto oficial del Estado, en un ámbito tan caro a la Iglesia como las prácticas fúnebres. Si este influjo se percibió con mayor fuerza en los reglamentos de la primera mitad del siglo XIX, para 1882 se observó una tendencia a tratar de diferenciar lo estatal de lo religioso. Así, se recortaron algunas funciones del párroco en favor de los profesionales de la medicina y se estableció un sector especial para los miembros de comunidades religiosas.

Las contradicciones y límites del republicanismo mendocino percibidos, en este caso, a través del examen de la normativa sobre los cementerios, dan cuenta del complejo y cambiante ambiente ideológico del siglo XIX. En efecto, junto a los vertiginosos cambios en todos los órdenes de la vida experimentados desde las revoluciones de independencia, se dieron notables continuidades y pervivencias que hicieron que todas las ideas políticas decimonónicas presentaran esta serie de fracturas y mutaciones que les dieron su especificidad. 
Finalmente, dado que este trabajo se ha limitado al análisis de la normativa, surge la pregunta respecto al nivel de las prácticas; es decir, si en la praxis alrededor de la muerte también incidieron las ideas republicanas, lo cual será trabajado en futuras investigaciones.

\section{Referencias bibliográficas}

Aguilar Rivera, J. A. (2002). Dos conceptos de república. En J. A. Aguilar Rivera y R. Rojas (Coords.), El republicanismo en Hispanoamérica. Ensayos de historia intelectual y política (pp. 57-85). México: Fondo de Cultura Económica.

Ahumada, M. (1860). Código de las leyes, decretos y acuerdos que sobre administración de justicia se ha dictado la provincia de Mendoza. Mendoza, Argentina: Imprenta del "El Constitucional".

Berstein, S. (Dir.). (2003). Les cultures politiques en France. París, Francia: Seuil.

Caballero, L. (2006). Acerca de los orígenes del Cementerio de la Capital de Mendoza. Mendoza, Argentina: Editorial de la Facultad de Filosofía y Letras, Universidad Nacional de Cuyo.

Caretta, G. y Zacca, I. (2007). Lugares para la muerte en el espacio meridional andino, Salta en el siglo XVIII. Memoria Americana, (15), 135-156.

Caretta, G. y Zacca, I. (2010). Deambulando entre las Eusapias: lugares de entierro y sociedad tras la ruptura independentista en Salta. En C. Folquer y S. Amenta (Eds.), Sociedad, Cristianismo y Política. Tejiendo historias locales (pp. 253280). Tucumán, Argentina: Cephia.

Caso Bello, Á. (2012). Interacciones discursivas entre 'república' y 'democracia' en la época de las independencias en el Río de la Plata (1808-1815): proximidades y lejanías semánticas. Ariadna histórica. Lenguajes, conceptos, metáforas, (1), 83- 
106.

http://www.ehu.es/ojs/index.php/Ariadna/article/view/4607/pdf

Di Meglio, G. (2009). República - Argentina/Río de la Plata. En J. Fernández Sebastián (Dir.), Diccionario político y social del mundo iberoamericano. La era de las revoluciones, 1750/1850. Tomo I (pp. 1270-1281). Madrid, España: Centro de Estudios Políticos y Constitucionales, Fundación Carolina, Sociedad Estatal de Conmemoraciones Culturales.

Entin, G. (2016). Dossier. El republicanismo en el mundo hispánico. Programa Interuniversitario de historia política. Recuperado de http://historiapolitica.com/dossiers/dossier-el-republicanismo-en-el-mundo-hispanico/

Fernández Sebastián, J. (2007). Iberconceptos. Hacia una idea transnacional de los conceptos políticos en el mundo iberoamericano. Isegoría. Revista de Filosofía Moral y Política, (37), 165-176.

Fogelman, P. (2004). Una economía espiritual de la salvación. Culpabilidad, purgatorio y acumulación de indulgencias en la era colonial. Andes, (15).

Fonseca, E. y Caraffini, C. (2015). De la sociedad colonial a la sociedad republicana: blancos, indios y negros. Revista Electrónica de Fuentes y Archivos, 6(6), 127139. Recuperado de http://www.refa.org.ar/contenido-autoresrevista.php?idAutor $=165$

García Garino, G. (2014). Representaciones sobre las instituciones democráticas: usos y significados a través de la prensa. Mendoza, 1852-1880. Ariadna histórica. Lenguajes, conceptos, metáforas, (3), 141-156. Recuperado de http://www.ehu.eus/ojs/index.php/Ariadna/article/view/10443/pdf_15

Guerra, F. X. (2000). La identidad republicana en la época de la independencia. En G. Sánchez Obregón y M. E. Wills Obregón (Eds.), Museo, memoria y misión. 
Misión de los museos nacionales para los ciudadanos del futuro (pp. 255-283). Bogotá, Colombia: Instituto Colombiano de Antropología e Historia.

Koselleck, R. (2004). Historia de los conceptos y conceptos de Historia. Ayer, (53), 27 45.

Lonmé, G. (2009). De la 'República' y otras repúblicas: la regeneración de un concepto,

En J. Fernández Sebastián, (Dir.), Diccionario político y social del mundo iberoamericano. La era de las revoluciones, 1750/1850. Tomo I (pp. 1253-1269). Madrid, España: Centro de Estudios Políticos y Constitucionales, - Fundación Carolina, - Sociedad Estatal de Conmemoraciones Culturales.Negretto, G. L. (2007). En repensant le républicanisme libéral en Amérique Latine. Alberdi et la constitution argentine de 1853. Amérique Latine Histoire et Mémoire. Les Cahiers ALHIM [en línea] 11. París, Francia: Université Paris-VIII. Recuperado de http://alhim.revues.org/962

Palti, E. (2007). El tiempo de la política. El siglo XIX reconsiderado. Buenos Aires, Argentina: Siglo XXI.

Real Academia Española. (2013). Mapa de diccionarios [en línea]. Recuperado de http://web.frl.es/ntllet/SrvltGUILoginNtlletPub

Riva, B. C. (2011). El perito médico en los delitos sexuales. Buenos Aires, 1850-1890 [tesis de licenciatura no publicada]. Facultad de Humanidades y Ciencias de la Educación, Universidad Nacional de La Plata. Recuperado dehttp://www.fuentesmemoria.fahce.unlp.edu.ar/tesis/te.411/te.411.pdf

Rosanvallon, P. (1992). Le sacre du citoyen. Histoire du suffrage universal en France. París, Francia: Gallimard.

Rosanvallon, P. (2002). Para una historia conceptual de lo político (nota de trabajo). Prismas. Revista de historia intelectual, (6), 123-133. 
Sabato, H. (2006). La reacción de América: la construcción de las repúblicas en el siglo XIX. En R. Chartier y A. Feros (Comps.), Europa, América y el mundo: tiempos históricos (pp. 263-280). Madrid/Barcelona, España: Marcial Pons.

Sirinelli, J. F. (2015). Del hogar al ágora. Para una historia cultural de lo político. Humha. Revista electrónica de Historia Cultural, 1 (1), 74-82.. Recuperado de http://revistas.uns.edu.ar/index.php/humha/article/view/265/222

Verdaguer, J. A. (1933). Historia Eclesiástica de Cuyo. Milán, Italia: Premiata Scuola Tipografica Salesiana. 